\title{
Evidence Collection for the Unconscious and Unconsented Patient
}

\author{
Rose Constantino', Carol Stewart ${ }^{2}$, Polly Campbell ${ }^{3}$, Barbara Moynihan 4 , Susan Kagan ${ }^{5}$, \\ Patricia Daugherty6, Kathleen Thimsen ${ }^{7}$, Lynda Tiefel ${ }^{8}$, Colleen 0’Brien', \\ Jennifer Johnson ${ }^{10}$ \\ ${ }^{1}$ Department of Health and Community Systems, University of Pittsburgh School of Nursing, Pittsburgh, USA \\ ${ }^{2}$ Harborview Medical Center, Seattle, USA \\ ${ }^{3}$ International Association of Forensic Nurses, Sexual Assault Forensic Examiner Program, Office of the Attorney \\ General, Augusta, USA \\ ${ }^{4}$ Quinnipiac University, Hamden, USA \\ ${ }^{5}$ Collarborative BScN Nursing Program, Seneca College of Applied Arts \& Technology, King City, Canada \\ ${ }^{6}$ Tennessee Department of Health, Health Related Boards/Office of Investigations, Greeneville, USA \\ ${ }^{7}$ Community Nursing Services, Southern Illinois University School of Nursing, Edwardsville, USA \\ ${ }^{8}$ Tiefel Legal Consulting, Tallahassee, USA \\ ${ }^{9}$ Wisconsin Department of Justice, Ridgeway, USA \\ ${ }^{10}$ Forensic Assessment Consultation and Treatment Program, Shawnee Mission Medical Center, Merriam, USA \\ Email: rco100@pitt.edu, carola@u.washington.edu, Polly.Campbell@Maine.gov, \\ Barbara.Moynihan@quinnipiac.edu, susan.kagan@senecacollege.ca, patricia.daugherty@tn.gov, \\ kthimse@siue.edu, diverrn@hotmail.com, cobrien@mhtc.net, jennifer@johnsonforensicInc.com
}

Received 20 February 2014; revised 22 March 2014; accepted 5 April 2014

Copyright $@ 2014$ by authors and Scientific Research Publishing Inc.

This work is licensed under the Creative Commons Attribution International License (CC BY).

http://creativecommons.org/licenses/by/4.0/

(c) (i) Open Access

\section{Abstract}

Forensic nurses are faced with making an ethical decision when an unconscious patient presents with signs of sexual assault. If the patient is unable to consent, the nurses need to decide whether or not to perform a forensic exam. Hospitals have policies in place regarding consent for emergency care, but not all of them consider the collection of forensic evidence. The window of opportunity for forensic collection may disappear before contacts are made or proper consent is established. Ethical, legal, and policy considerations that complicate this scenario are discussed.

\section{Keywords}

Forensics; Forensic Nursing; Sexual Assault; Ethical Considerations in Sexual Assault; Legal Aspect of Sexual Assault; Informed Consent in Sexual Assault 


\section{Background}

Forensic nursing practice takes place in the context of a health care system as it intersects with the social, public health and criminal justice systems [1]. This complex integration of systems requires the forensic nurse to evaluate multiple concerns when conducting a patient assessment. Evidence collection becomes a dilemma in the unconscious patient, as illustrated in the following case. Forensic nurses need a model for ethical reasoning in order to provide care aligned with needs of patients and with ethical standards shared by nursing professionals. Whatever model is used, it must consider the patient as he or she intersects in this complex system. No system is ever static and it is important to review professional guidelines and practices as more evidenced-based information becomes available. Models for ethical reasoning should reflect on all the relevant issues of a patient case or situation. One model for ethical reasoning suggested is the Nurses Ethical Reasoning Model [2].

\section{Case Study}

It starts as another hectic Saturday night in the emergency department, when an unconscious woman with serious injuries arrives by ambulance. Immediately the staff suspects sexual assault due to the nature of her injuries, the placement of her clothes on her body, and the location where she was found. The forensic nurse is consulted. No other details are known; she is intubated and prepped for surgery with placement of an indwelling urinary catheter. The forensic nurse knows the importance of collecting valuable evidence before it is lost or destroyed during surgical preparation, or during the process of providing medical care. Next of kin or significant others are not yet identified or located.

It is important to collect evidence quickly when sexual assault is suspected, as forensic evidence is fragile and can quickly disappear. While the life-saving procedures are covered under the principle of implied consent [3], the collection of evidence is not necessarily covered in the state or province where many nurses practice. Forensic nurses confronted with this situation must know the guidelines for evidence collection.

\section{Literature Review}

Discussion in the literature primarily focuses on the unconscious female sexual assault patient. The British Columbia Network [4] evaluated this forensic issue and made the decision to oppose collection of evidence in the unconscious sexual assault patient. They evaluated the literature, involved their community of professionals along with input from sexual assault survivors as they considered their policy. Their opposition follows from both their legal and ethical stance.

From the legal perspective, the British Columbia Network (BCN) used the Canadian Medical Association that only allows the provision of life-saving medical procedures without consent. Collection of evidence is not a life-saving procedure. From the ethical perspective, the BCN used a feminist framework, focusing on women's health issues and the adherence to the philosophy of the importance of safety, autonomy, and returning control to the survivor. The BCN contends that performing evidence collection without consent may make patients feel loss of control; thus, they maintain their perspective is consistent with their philosophy and what they know of their community.

The BCN's evaluation assumes that evidence collection is an invasive, non-medical procedure that would submit a person to a demeaning procedure that may victimize the individual even further. They also maintain that evidence collection under these circumstances supports a legal system that the patient may or may not use. Although the BCN is conclusive about forgoing a forensic evaluation with collection of evidence, they did allow an exception that forensic evidence may be taken if discovered during the course of the medical evaluation and kept until consent is obtained.

The case for promoting the collection of evidence is primarily done with caveats, or conditions that require patient anonymity, or a provision for holding evidence until consent for release is obtained either by the patient, or a surrogate decision-maker such as a family member, guardian or judge. Pierce-Weeks and Campbell [5] argue that evidence collection has become a standard of care in the Emergency Department and to not take evidence is to fall short of that gold standard of care. They maintain that non-emergent care is routinely given along with emergent care; therefore a thorough medical/forensic examination does not violate any standards of care. Evidence collection during the examination would not be considered invasive or in violation of the patient. Some states allow for the collection of evidence in an "anonymous fashion, without report to law enforcement; 
in this case the identity of the patient is kept confidential until the patient decides whether to make a report” (p. 108). These states have given thoughtful consideration to patient choice, autonomy, consent, and confidentiality.

Carr and Moetus [6] reviewed both [4] [5] articles. While acknowledging the importance of the Lee article [4], they did not agree a strong case was made against collecting evidence. They agreed with Pierce-Weeks, to collect evidence and wait for consent from the patient or the courts. In addition, they advocate "Many patients will want the choice on whether to talk to the police or report a sexual assault. If the evidence is not gathered, then part of that choice is taken away from the patient” (p. 649). Evidence can be collected and saved until the patient requests, or the court orders the evidence be turned over to the police. If no report is made, or court order is received, the evidence would be destroyed.

These articles provide a solid place to start examination of the complexity of the issues. Other articles are discussed further regarding how to develop protocols or provide further guidance in clinical situations. Before turning to further discussion of the issues, it is helpful to review the basic elements of the forensic nursing exam.

\section{Forensic Examination}

The forensic examination includes evidence collection for possible DNA with a thorough assessment and documentation of injury. The forensic sexual assault exam is similar to all forensic exams and is a systematic procedure used in assessing, collecting, documenting, and packaging of samples [7]. In the specific case of sexual assault, a sexual assault forensic kit is often employed to guide the collection of evidence. Photography is frequently used to supplement documentation. The forensic nurse is knowledgeable in the importance of preserving evidence and the chain of custody to provide samples for crime investigation [8]. The forensic exam may include information to the patient and provision of medication for sexually transmitted diseases and pregnancy prevention. The collection of evidence has a 72 - 120 hour time frame for optimal recovery of specimens, requiring response from a forensic nurse [9].

Forensic nurses know that responses to rape are highly personal and vary among victims. Loss of control is a common response to sexual assault, along with fear, embarrassment, and anger. When a forensic nurse provides evidence to prove an assault occurred, it can assist a patient in finding closure. If that evidence leads to prosecution, it assists in helping the patient feel safe.

Dumont, White, and McGregor [10] found that despite a wide range of feelings, the majority of women were primarily concerned about their physical and mental well-being. They also found that "while many women felt distressed while the sexual assault kit was being administered, most simultaneously reported a sense of 'doing something' positive for themselves” (p. 779). When a patient is conscious the forensic nurse reviews all aspects of the exam and asks for consent throughout. Consent would include the exam and treatment, photography and release of information. Consent is verbally requested again as the exam progresses so the patient has a better understanding of what it entails, and has complete control of the exam [11]. The informed consent process has four distinct parts, including explanation of the risks, benefits, alternatives, and consequences of the procedure or treatment. It is equally important to inform patients of the consequences if the treatment of procedure is not performed.

\section{Ethics and Informed Consent}

The process of seeking informed consent is a routine part of patient care. It is the basis for our understanding and respect for individual rights. Informed consent originates from the legal and ethical right the patient has to direct what happens to her/his body and from the ethical duty of the provider to involve the patient in her/his health care [12].

The purpose and intent of informed consent for health care in bioethical literature has been well documented. The purpose of asking patients for consent is to validate respect for individual autonomy and the right to self-determination. Beauchamp and Childress [13] detail informed consent as the ethical principle of autonomy and protecting a patient's right to choice, stating "It requires an attempt to instill relevant understanding, to avoid forms of manipulation, and to respect persons' rights” (p. 121). Jonsen, Siegler, and Winslade [14] agree, stating "Patient preferences are ethically significant because they manifest the value of personal autonomy that is deeply rooted in our culture" [14].

When an unconscious patient presents, informed consent is not possible. Hospitals have consent protocols when an individual cannot consent. Most often, a relative or guardian will provide consent under these condi- 
tions. The ethical basis for allowing next of kin or a legal guardian to consent is also based on autonomy or selfdetermination. Next of kin or legal guardians provide consent based on their knowledge of what the patient would want to the extent it can be determined. If the patient's preferences are unknown, the patient's best interests are considered [14] [15].

\subsection{Ethical Implications for Forensic Nursing Practice}

There are two avenues to explore in the discussion of ethics involving the forensic nurse role. First is the role of professional codes of ethics within healthcare and the forensic exam. The second consideration is the clinical provision of care when principles alone are in conflict or insufficient as a guide for a particular case.

Codes of ethics are established in many professions and provide a guide to the community and patients regarding professional conduct. Codes are established to help provide guidance with role obligations and responsibilities. Beauchamp and Childress [13] believe there is also concern codes may be "vague, incomplete, or misused to protect the profession" rather than the patient. Beauchamp also warns that codes may "oversimplify moral requirements" [13]. Downs and Swienton [3] reviews a 2009 report from the national Academy of Sciences that suggest the disparity of the existing codes of ethics. Veatch [16] states another concern that individuals may belong to several organizations in which codes may conflict.

While acknowledging this concern, professional codes can provide guidance when derived from ethical principles [13], and are used as a tool in making decisions. Barnett [17] on forensic sciences gives examples of how the codes of ethics may address particular circumstances in handling forensic evidence. According to Barnett "Codes of ethics should enable practitioners to justify a particular course of action in a particular circumstance" (p. 10).

The American Nurses Association (ANA) Code of Ethics for Nurses [18]-[20] serves as a guide for nurses in carrying out their professional responsibilities. The ANA code reflects nursing's traditional concern for the sick, injured and vulnerable; thereby promoting social justice. It incorporates ethical principles as a guide for actions and addresses nurses' responsibilities to individual patients, and as members of the health care team, the community and the profession. An example is in provision four, which states, "moral accountability does not mean congruence with others, but rather nurses will be able to adequately defend and justify their decisions on moral grounds" [18].

\subsection{Ethical Issues}

Autonomy, justice, veracity, and fidelity are key principles of ethics. Autonomy is respect for the right of all persons to self-determination and independence. The principle of autonomy frames the informed consent process in healthcare [1] [12] [13]. Justice demands the forensic nurse is fair in all interactions and communications. Justice makes certain that policies and procedures in forensic nursing practice are consistently and equitably applied without selective dispensation because each person is unique [17]-[20]. Veracity comprises truthfulness, trustworthiness, and transparency. To apply the ethical principle of veracity, an environment of openness, honesty, trustworthiness, and transparency must consistently be showcased [21]. Fidelity means loyalty and faithfulness to persons and entities. This principle allows others to trust the forensic nurse for guidance in decision-making, safety, and well-being.

Forensic nurses are obligated to provide care that is ethical and safe. The forensic nurse has an ethical duty to protect others from harm (non-malfeasance) and to provide service for the good of the patient (beneficence). Practicing non-malfeasance and beneficence requires the forensic nurse to consider ones' physical, emotional, and spiritual needs; respect individuality; and focus on the multidisciplinary approach to advocacy [1] [20]-[22].

The second part of the ethical discussion is in the clinical provision of care. Ethical principles and theories provide a backdrop for ethical decision-making but may not provide specific direction for translation into practice, especially when there are competing principles. In the case of the unconsented patient within the context of the urgent forensic exam, there are conflicting professional opinions about whether collection should take place.

\subsection{Ethical Decision Making}

There are a number of ethical decision-making guides that employ similar methods. Essential elements in reviewing cases should include the goals and values of the patient, if known; along with any socio-cultural rele- 
vant information. All the facts of a case need to be discussed and reviewed among providers and decision-makers along with the consequences of each potential decision [18]-[20].

Fairchild's Nurses' Ethical Reasoning Skills (NERS) model [2] is one example of an ethical framework to address ethical issues for forensic nursing dilemmas in a complex system. The NERS model is designed to engage the nurse in systems thinking, with meta-cognitive skills of reflection, reasoning, and review of competing principles in complex patient care situations. It recognizes being mindful of one's individual and collective actions in the context of professional standards of nursing practice. Before using this tool or any other, it is important for nurses and programs to address all considerations and facts of a case while reflecting on the importance and relevance of all issues.

\section{Legal Considerations}

While it is beyond the purpose of this paper to discuss all legal implications of taking forensic evidence collection on the unconsented and unconscious patient, it is important to recognize that it is often legal considerations that deter nurses from providing forensic evidence collection in these situations. Since legal considerations vary among countries, states, and provinces, each provider needs to know how these considerations affect them and their practice. In the United States, it is generally regarded that the Emergency Medical Treatment and Labor Act (EMTALA) enacted by Congress in 1986 provides a blanket protection for emergency services when a patient has life-threatening injuries and cannot consent [1] [22]-[24].

Each country or state promulgates its own laws, which apply only in that particular jurisdiction. In Canada, it is not considered a medical necessity to obtain DNA from an unconscious patient. Some areas in Canada have developed regional guidelines or legislation related to evidence collection with unconscious patients. Without guidelines, it is argued that healthcare providers who collect evidence from unconscious unconsented patients can be charged with battery (intentional tort) and/or negligence (unintentional tort) [1]. There are three general areas of law: 1) criminal law includes all federal and state laws that relate to society as a whole and deals with felonies and misdemeanors; 2) tort law, also known as civil law, includes laws dealing with individuals and their relationships with each other; and 3) public law is associated with direct government involvement. It is under the ambit of tort law that the forensic nurse may be involved or consulted in caring for an unconscious, unconsented and unrepresented patient in the ED [1].

\section{The Legal Theories in the United States of America}

Torts are wrongful, crooked, or tortious acts or ommissions that harm another classified as 1) intentional torst, 2) a quasi-intentional torts, or 3) unintentional torts-professional negligence. In tort law, the common principle is that persons injured by a tortfeasor are to be compensated and injurious acts or omissions are to be discouraged [1] [23].

Intentional torts are intentional or willful acts or omissions that injure or harm another. An intentional tort requires the person committing the act has the requisite knowledge and will to commit the wrongful act. The focus of an intentional tort is on intent and consent or lack of consent. Intentional torts include assault, battery, false imprisonment, and intentional infliction of emotional distress. Battery is implicated when forensic nurses examine and collect specimens from an unconscious unconsented patient. Battery is defined as harmful or offensive touching of another without his or her consent or without a legally justifiable reason; the subject of the battery need not be aware or conscious. When forensic nurses examine unconsented patients for the purpose of collecting specimens, they are concerned with the legal implication of battery [1] [23]-[25].

Unintentional torts include personal injuries suffered as a result of the commission of an act without permission, or the omission of an act. Unlike intentional or quasi-intentional torts (which generally require the alleged defendant to have the specific intent to cause injury), unintentional torts do not require intent to harm. An unintentional tort requires only that the alleged "tortfeasor" act in a manner in which a reasonable person would not act under similar circumstances, and that the commission or omission of an act results in injury to another. Understanding the principles of malpractice law enables forensic nurses to assess current practices in their own jurisdictions and take action or respond to issues and questions to provide quality care and achieve optimal patient outcomes [1] [23]-[25].

Professional malpractice or negligence is the act or the omission of an act by a professional individual or legal entity that constitutes failure to exercise care in the performance of professional duties. The underlying legal 
theory is that the practice of a learned profession requires specific education, learning, and/or experience beyond that of the average person. The profession is required to set its own standards, and therefore the law holds professionals (including nurses) to the minimum standard of care that would be required of a competent professional in the same field under similar circumstances [23]-[25].

Forensic nurses need to know the law requires only that they be reasonable: as reasonable trained professionals they follow the standards of care enunciated by their profession. Negligence, professional malpractice or informed consent are unintentional wrongdoings in the form of failure to meet a standard of care that any reasonably prudent healthcare provider would meet, possessing similar knowledge and skills under comparable circumstances.

\section{Professional Guidance}

Forensic nurses and institutions are directed to look for information and guidance from the professional literature and professional associations. This provides a context to evaluate recommendations already in place. Professional institutions have varying opinions on the collection of forensic evidence, reinforcing the conflict that exists and the need for forensic nurses to work with all stakeholders in resolving this conflict within their own jurisdictions.

Guidelines that address forensic evidence collection are found within national protocols and legislation, and integrated to professional guidelines. The National Institute of Justice SAFE Protocol updated in 2013, recognizes the importance of the forensic exam with a victim-centered approach. Their direction for forensic collection of evidence on the unconscious patient centers on institutions evaluating the best care of the patient with emphasis on policy formation and respect for patient's autonomy.

The Violence Against Women Act (VAWA), recognizes the importance of a sexual assault evidentiary examination. Downs and Swienten [3] argue the importance of this legislation and that the unconscious patient could be given the sexual assault examination without having to report to police as ethically acceptable because it allows choice for the victim. Congress, in February 2013 reauthorized VAWA [26].

The position statement for The Emergency Nurses Association (ENA) [27] embodies the importance of evidence collection although not specifying issues around the unconscious patient. Their guidelines combine the importance of forensic evidence collection along with emergency nursing care practice.

The American College of Obstetrics and Gynecology recognizes the medical-legal needs of the sexual assault patient. They assert that forensic nurses have the responsibility to be aware of policy requirements and laws in their own states, when collecting forensic evidence [28] [29].

\subsection{Examples of Policy and Guideline Development}

Guidelines are developed within communities to address their patient populations. The Ontario Network presents [30] an algorithm created to help the forensic nurse and team working with the unconscious patient. In their algorithm, evidence collection is allowed for an unconscious patient as it provides a vulnerable population with the optimal opportunity to pursue prosecution.

Professional guidelines in medical care include the importance of evidence collection. An example of this is from a New York emergency department [7] guideline that provides, "The medical needs of the patient are paramount. The next concern, however, must be the recognition, collection, and proper handling of forensic evidence from patients that received gunshot or stab wounds or were severely assaulted" [7].

Maine started the process to address the issue of collecting forensic evidence from an unconscious patient. Maine allows the anonymous collection of evidence for a comatose patient. Evidence is held until the patient regains consciousness or decides what to do with the evidence. If the patient does not regain consciousness after 60 days, the courts make the decision. Maine's legislation incorporates an implied consent clause, and a provision granting immunity from liability for the clinician [31]. Other jurisdictions may require a search warrant to collect evidence from the unconscious patient [5].

Policy and guideline development for collection of evidence on the unconscious and unconsented patient are important in meeting the challenges of this situation. Policy development should include all providers including medical, nursing, and social work, and should enlist input from advocacy groups, ethics committees, administration, and state or province law professionals. Policy development should include a systematic review of available evidence-based literature and information. Regulations from states and provinces will impact how care is 
provided [32] [33].

\section{Discussion}

Although there are many dimensions of collecting forensic evidence on the unconscious and unconsented patient, the legal and ethical ramifications are most predominant. Forensic nurses need to evaluate these issues within their own programs.

If an examination is not medically necessary, legal concerns arise regarding issues of consent in an emergent situation. Nurses are concerned about charges of battery. While this is a definite concern, standards of care that incorporate forensic collection are found in professional guidelines developed in hospitals and communities to address this issue. Although professional guidelines are not generally considered legal documents, they often help guide lawmakers and stakeholders.

Ethically, the forensic nurse must respect patient autonomy and individual rights while providing the best possible care. Whether to collect or not collect evidence, both have valid ethical positions, as they attempt to provide the best care for the patient. Patients are best served by using an ethical reasoning model in collaboration with all caregivers, stakeholders, and any known wishes of the patient.

When professionals disagree about evidence collection, it is not because one is ethical and one is not. Disagreement may exist behind the weight of competing principles or goals of care, as each avenue of choice is considered. While legal implications are strongly regarded and can become the default to which a forensic nurse feels compelled to rely upon, it is important to remember that the legal system is one aspect of this issue. In the formation of laws, when professional guidance is sought, nursing organizations can offer best practice guidelines to lawmakers. Patients are best served when these types of issues are addressed beforehand, using their institution's guidelines for forensic evidence collection.

\section{Summary}

The forensic nurse should consult their hospital's policies or guidelines for instruction on how to react to an unconscious, unconsented sexual assault patient. If guidelines exist, they should be reviewed with all the providers and evaluated for each individual patient situation. If they do not exist, the forensic nurse or sexual assault response team should initiate discussion among all stakeholders before an unconscious patient presents. If an unconscious patient presents to the emergency room and there is no policy in place, a discussion and decision with all involved providers and patient family or advocate, should happen immediately, even if it is time limited. Consequences of each scenario or decision should be reviewed and evaluated by providers [32]. The discussion and final decision should be documented.

\section{Conclusions}

Ethical dilemmas are part of every nurse's role, but the blurred boundaries and conflicting role expectations of nurses working in forensic settings magnify the impact of ethical decision making on forensic nursing outcomes. The intersection of criminal justice with health care systems and the balancing of rights between individuals and society are hallmarks of forensic events. According to Hammer, et al. [33] the protection of vulnerable individual human rights is a common issue addressed in forensic settings, in which nurses are confronted between the rights of individuals, a therapeutic and helping relationship, and obligations to preserve evidence security and control. To our international colleagues, the authors would like to invite the global community to embrace conversation and dialogue on developing evidence-based policies related to the ethical, legal and sociocultural standards and the rule of law in evidence collection with the unconscious and unconsented patient in specific healthcare systems, jurisdictions, or countries. Although jurisdictions and countries vary in rules, regulations and human rights policies, we are united in the ethical principles of autonomy and justice for all. The first author would like to offer time and experience in international collaborative networking through mobile technology or other networking platforms in ethical, legal and sociocultural issues policy discussion.

\section{References}

[1] Constantino, R.E., Zalon, M.L. and Young, S.E. (2013) The Ethical, Legal, and Sociocultural Issues in Forensic Nursing. In: Constantino, R.E., Crane, P.A. and Young, S.E., Eds., Forensic Nursing: Evidence-Based Principles and Prac- 
tice, F. A. Davis, Philadelphia.

[2] Fairchild, R.M. (2010) Practical Ethical Theory for Nurses Responding to Complexity in Care. Nursing Ethics, 17, 353-362. http://dx.doi.org/10.1177/0969733010361442

[3] Downs, J.C. and Swienton, A. (2012) Ethics in Forensic Science. Academic Press, Boston.

[4] Lee, P.M. (2001) In the Absence of Consent: Sexual Assault, Unconsciousness and Forensic Evidence. Women's Health Reports. British Columbia Centre of Excellence for Women's Health.

[5] Pierce-Weeks, J. and Campbell, P. (2008) The Challenges Forensic Nurses Face When Their Patient Is Comatose: Addressing the Needs of Our Most Vulnerable Patient Population. Journal of Forensic Nursing, 4, 104-110.

[6] Carr, M. and Moettus, A. (2010) Developing a Policy for Sexual Assault Examinations on Incapacitated Patients and Patients Unable to Give Consent, Global Health Governance. Journal of Law, Medicine, and Ethics, 38, 647-653. http://dx.doi.org/10.1111/j.1748-720X.2010.00518.x

[7] Eisert, P., Eldredge, K., Hartlaub, T., Huggins, E., Keirn, G., Obrien, P., Rozzi, H., Pugh, L. and March, K. (2010) CSI: New @ York, Development of Forensic Evidence Collection Guidelines for the Emergency Department. Critical Care Nursing Quarterly, 33, 190-199. http://dx.doi.org/10.1097/CNQ.0b013e3181d913b4

[8] Linden, J. (2011) Care of the Adult Patient after Sexual Assault. New England Journal of Medicine, 365, 834-841. http://dx.doi.org/10.1056/NEJMcp1102869

[9] Saferstein, R. (2011) Principles of Forensic Evidence Collection and Preservation. In: Lynch, V.A. and Duvall, J.B., Eds., Forensic Nursing Science, Elsevier Mosby, Philadelphia, 101-108.

[10] Dumont, J., White, D. and MacGregor, M. (2009) Investigating the Medical Forensic Examination from the Perspectives of Sexually-Assaulted Women. Social Science and Medicine, 68, 774-780. http://dx.doi.org/10.1016/j.socscimed.2008.11.010

[11] Chasson, S. (2011) Legal Issues for the Forensic Nurse. In: Lynch, V.A. and Duvall, J.B., Eds., Forensic Nursing Science, Elsevier Mosby, Philadelphia, 445-451.

[12] http://depts.washington.edu/bioethx/topics/consent.html

[13] Beauchamp, T.L. and Childress, J.F. (2013) Principles of Biomedical Ethics. 8th Edition, Oxford University Press, New York.

[14] Jonsen, A., Siegler, M. and Winslade, W. (2006) Clinical Ethics: A Practical Approach to Ethical Decisions in Clinical Medicine, McGraw-Hill Companies Inc., New York.

[15] Buchanan, A. and Brock, D. (1992) Deciding for Others: The Ethics of Surrogate Decision Making. Cambridge University Press, New York.

[16] Veatch, R. (1997) Medical Ethics: An Introduction. In: Veatch, R., Ed., Medical Ethics, 2nd Edition, Jones and Bartlett Publishers, Boston.

[17] Barnett, P. (2001) Ethics in Forensic Science: Professional Standards for the Practice of Criminalistics. CRC Press, New York. http://dx.doi.org/10.1201/9781420041620

[18] Matt, S.B. (2012) Ethical and Legal Issues Associated with Bullying in the Nursing Profession. Journal of Nursing Law, 15, 9-13.

[19] Maine Revised Statutes Annotated (MRSA 2986). http://www.mainelegislature.org/ros/LOM/lom122nd/14pub501-550/Pub501-550-121.htm

[20] American Nurses Association (2008) Code of Ethics for Nurses with Interpretive Statements. American Nurses Association, Washington DC.

[21] American Nurses Association (2010) Nursing's Social Policy Statement: The Essence of the Profession. Nursesbooks.org, Silver Spring.

[22] American Nurses Association and International Association for Forensic Nurses (2009) Scope and Standards for Forensic Nursing Practice. American Nurses Association, Silver Spring.

[23] Constantino, R.E. and Privitera, P.R. (2011) Understanding Ethical, Legal, and Sociocultural Issues in Workplace Violence Prevention. In: Privitera, M.R., Ed., Workplace Violence in Mental and General Healthcare Settings, Jones and Bartlett Publishers, Boston.

[24] Carter-Snell, C.J. (2013) Violence: Sexual Assault and the Forensic Nurse. In: Constantino, R.E., Crane, P.A. and Young, S.E., Eds., Forensic Nursing: Evidence-Based Principles and Practice, F. A. Davis, Philadelphia.

[25] Northrop, C.E. and Kelly, M.E. (1987) Legal Issues in Nursing. Mosby, Washington DC.

[26] US Department of Justice (2004) A National Protocol for Sexual Assault Medical Forensic Examinations: Adults/Adolescents. Office on Violence against Women. 
[27] Emergency Nurses Association Position Statement on Forensic Evidence Collection (2010) Emergency Nurses Association.

[28] http://www.acog.org/Resources_And_Publications/Committee_Opinions/Committee_on_Health_Care_for_Underserve d_Women/Sexual_Assault

[29] Macdonald, S. and Norris, P. (2007) Guidelines for the Collection of Forensic Evidence from the Person Who Is Unable to Provide Consent Provincial Coordinator for Sexual Assault \& Domestic Violence Treatment Centres in Ontario. Ontario Network of Sexual Assault \& Domestic Violence Treatment Centres.

[30] Williams, J. and Williams, D. (2013) Disaster Forensic Nursing. In: Constantino, R.E., Crane, P.A. and Young, S.E., Eds., Forensic Nursing: Evidence-Based Principles and Practice, F. A. Davis, Philadelphia.

[31] Hammer, R.M., Moynihan, B. and Pagliaro, E.M. (2013) Vulnerable Populations. Forensic Nursing: A Handbook for Practice, Jones \& Bartlett, Burlington.

[32] http://www.scu.edu/ethics/practicing/decision/framework.html

[33] http://josephsoninstitute.org/MED/index.html 